\title{
Variability of Performance Indices of Photovoltaic Solar Panels in Operating Conditions in the Littoral Zone of Cameroon
}

\author{
Regine Fouda Bella1,2, Salomé Ndjakomo Essiane1,2,3, Simon Koumi Ngoh1,2, Boris Fouotsap1,2 \\ ${ }^{1}$ Higher Technical Teacher's Training College of Ebolowa, University of Yaoundé I, Yaoundé, Cameroon \\ ${ }^{2}$ Laboratory of Technology and Applied Sciences, The University of Douala, Douala, Cameroon \\ ${ }^{3}$ Laboratory of Electrical Engineering, Mechatronics and Signal Processing, University of Yaoundé I, Yaoundé, Cameroon \\ Email: foudareginediane@gmail.com
}

How to cite this paper: Bella, R.F., Essiane, S.N., Ngoh, S.K. and Fouotsa, B. (2021) Variability of Performance Indices of Photovoltaic Solar Panels in Operating Conditions in the Littoral Zone of Cameroon. Computational Water, Energy, and Environmental Engineering, 10, 108-116. https://doi.org/10.4236/cweee.2021.103008

Received: April 28, 2021

Accepted: June 28, 2021

Published: July 1, 2021

Copyright $\odot 2021$ by author(s) and Scientific Research Publishing Inc. This work is licensed under the Creative Commons Attribution International License (CC BY 4.0).

http://creativecommons.org/licenses/by/4.0/

\begin{abstract}
Photovoltaic cells are generally manufactured under standard test conditions. The operating conditions, very often induce performance losses different from those initially given by the manufacturer. This article presents an experimental acquisition and analysis system that integrates the synthetic efficiency ratio (SER) as a hybrid analysis tool to evaluate the performance of a monocrystalline photovoltaic solar panel, in this case the LW-MS90 panel in the city of Douala. The meteorological data obtained experimentally was used to evaluate these performances according to the manufacturer's model in MATLAB/Simulink. By comparison with the experimental performances, the results quantify through a certain number of indices, a minimal power drop according to the acquired irradiance estimated at $3.45 \%$. The interest of this approach is to contribute to the prediction of the operating performance of PV panels in the installation phase in non-standard areas.
\end{abstract}

\section{Keywords}

Photovoltaic Panel, Performance, Synthetic Efficiency

\section{Introduction}

Energy is an essential factor for any society that sees itself emerging in the socio-economic and socio-industrial field. It brings considerable satisfaction to the economic rendering and contributes strongly to sustainable development. However, some energy sources are becoming more and more problematic with the soaring oil prices on the one hand and the environmental consequences induced using fossil resources on the other [1]. Today, different forms of renewable 
energy (solar, wind, hydro, biomass...) offer a high degree of flexibility and reliability to mitigate the energy deficit. Sub-Saharan Africa has a great potential for renewable energy. Solar energy, has been estimated 3500 hours of sunshine per year and an energy potential of $2650 \mathrm{kWh} / \mathrm{m}^{2} /$ year [2] [3]. The use of this potential has improved significantly in recent years with the development of conversion and conditioning technologies. However, manufacturers do not sufficiently consider the environmental conditions in which photovoltaic modules are required to operate (temperature, humidity, UV irradiation, dust, etc.). The technical characteristics are given in the standard test conditions (STC) corresponding to a temperature of $25^{\circ} \mathrm{C}$ and a sunshine of $1000 \mathrm{~W} / \mathrm{m}^{2}$ for manufacturer's guarantees of around 25 years. The operating conditions of photovoltaic systems in Sahelian Africa, characterized by an arid climatology, have an impact on their lifespan and performance [4] [5]. There is a scientific barrier to the actual estimation of lifetime as a function of the degradation of module performance. In addition, there is lack of information on the different degradation modes of PV modules and their impact on module reliability [6]. Research on photovoltaic modules is focused on the development of new technologies without sufficient feedback on those that are already operational [2] [7]. In Cameroon and in the sub-Saharan African region, we have not identified any research structure that is interested in this issue. Thus, a good understanding of the behaviour and performance evolution of photovoltaic modules during their life cycle would be a great asset for the development of the sector in Cameroon. Our study is mainly focused on the evaluation of the performance of monocrystalline photovoltaic modules, which constitute the dominant technology with $93 \%$ in the Cameroonian market [1] [8]. The tools and methods used during the calculation procedures of the performance indicators are compared based on three values of the Synthetic Efficiency Ratio (SER). This indicator (called "Overall Equipment Effective Ness OEE") has become, through the NFE 60-182 standard, one of the performance indicators of production systems [9] [10]. It is currently recognized as a fundamental tool for evaluating the performance of production systems and gives an account of the effective use of a means of production and makes it possible to identify losses. It allows a better understanding and optimization of production flows and provides tools to help organize an appropriate maintenance policy. The benefits of this article are structured as follows:

- Implementation of a system to evaluate PV performance indicators in the city of Douala, Cameroon;

- Prediction of performance under standard manufacturing and use conditions in the city of Douala;

- Comparison of the performance of the MATLAB/Simulink model of the LW-MS90 panel with that obtained experimentally.

This work is organized according to the following sections: Section 2 provides the methodology that will enable us to evaluate the performance indicators; Section 3 presents the results obtained experimentally and in simulation on MATLAB/Simulink. A comparative analysis is invested between the simulation 
and experimental study. In Section 4, we have the conclusion.

\section{Method of Evaluating Performance Indices}

In order to solve a problem, information must be collected, and scientific tools are used to reach a conclusion based on the data collected. In order to evaluate the performance of our photovoltaic system, standards and mathematical tools are needed. The SER is used to identify losses and it is an excellent tool for investigation. In order to allow a better evaluation of the performance of the production systems, two main procedures are used to determine the SRT: on the one hand, the productivity aspect which is defined as a ratio of the number of good products to the number of theoretically achievable products. On the other hand, the aspect of operational reliability is considered and allows the OEE to be defined as a ratio of the useful time (time during which good products are produced) to the required time (time during which a certain number of products would theoretically be produced). This second approach uses rates (Performance rate (Pr), Quality rate (Qr) and Operational Availability (OA)), which will be used as data for the modelling of the efficiency of production systems by state machines.

\subsection{Methodology for Assessing the Efficiency of the Photovoltaic System}

The efficiency of a generation entity is a global-local performance indicator, which can be calculated for any level of decomposition (system or subsystem). The link between all the efficiencies of a production facility is created directly from the intrinsic links between the tasks and/or physical components of the production facility. Efficiency is therefore a function of availability, quality and productivity. It can be extended to safety or any other peripheral element affecting the performance of the tool such as a photovoltaic system in the case of this paper. However, the efficiency of a production system is the calculation of the performance ratio (PR) which allows to account for the quality of operation of an installation independently of the irradiation or the power. It is expressed in kilowatt/hours [1].

$$
\mathrm{PR}=\frac{\text { Real production }(\mathrm{kWh})}{\text { theoretical production }(\mathrm{kWh})}
$$

\subsection{Current Efficiency}

This is the rate of electrical power quality obtained from experimental tests. Current efficiency is the ratio of the measured current to the rated current [6].

$$
T_{q i}=\frac{\text { practical current }}{\text { Rated current }}
$$

\subsection{Voltage Efficiency}

This is the quality rate in electrical voltage obtained from our tests, here called practical voltage, in relation to the nominal voltage of the monocrystalline 
photovoltaic panel given by the manufacturer. The voltage efficiency is the ratio of the electrical voltage obtained from our tests to the electrical voltage given by the manufacturer of the solar photovoltaic panel. It is given by the following formula: monocrystalline type operating at a temperature of $25^{\circ} \mathrm{C}$ [9].

$$
T_{q u}=\frac{\text { Practical voltage }}{\text { Rated voltage }}
$$

\subsection{Power Efficiency}

This is the product of the quality rate in electric current by the quality rate in electric voltage obtained from our tests carried out on the acquisition system of the monocrystalline photovoltaic solar panel operating at a temperature of $25^{\circ} \mathrm{C}$ [1] [6].

$$
T_{q p}=T_{q u} * T_{q i}
$$

\subsection{Synthetic Efficiency Ratio}

The SER is an effective indicator of productivity that reflects the effective use of a production facility. It quantifies the performance of a production system over a well-defined period. The TRS is an excellent investigation tool; a means of analysing the efficiency of processes. It allows practical data obtained from tests to be compared with those given by the manufacturer in order to evaluate performance indicators. Mathematically, it is defined by Equation (5) [1].

$$
\mathrm{SER}=T_{q} * T_{p} * D_{o}
$$

The factors that define the SER are:

- $T_{q}$ Quality Rate: This is equal to the ratio of the yield obtained from the tests to the ratio of the nominal yield of the monocrystalline solar panel.

- $T_{p}$ The Performance Rate: It is equal to the ratio of the power obtained from the tests by the nominal power given by the manufacturer of the monocrystalline photovoltaic panel.

- OA Operational Availability: This is the ratio of the operating time (OT) to the required time (RT). It is given by the following formula [11].

$$
\mathrm{OA}=\frac{\mathrm{OT}}{\mathrm{RT}}
$$

1) Synoptic of the performance evaluation system

The analysis and evaluation of performance is based on the principle described in Figure 1. This principle is established through the work carried out by [12] very recently.

2) Equation of the performance prediction algorithm

Figure 2 describes the experimental chopper proposed in [13].

Consider Equation (7) [13] [14] [15] which describe the mean state model in Figure 2, a predictive equation which is given by (8) [5]. 


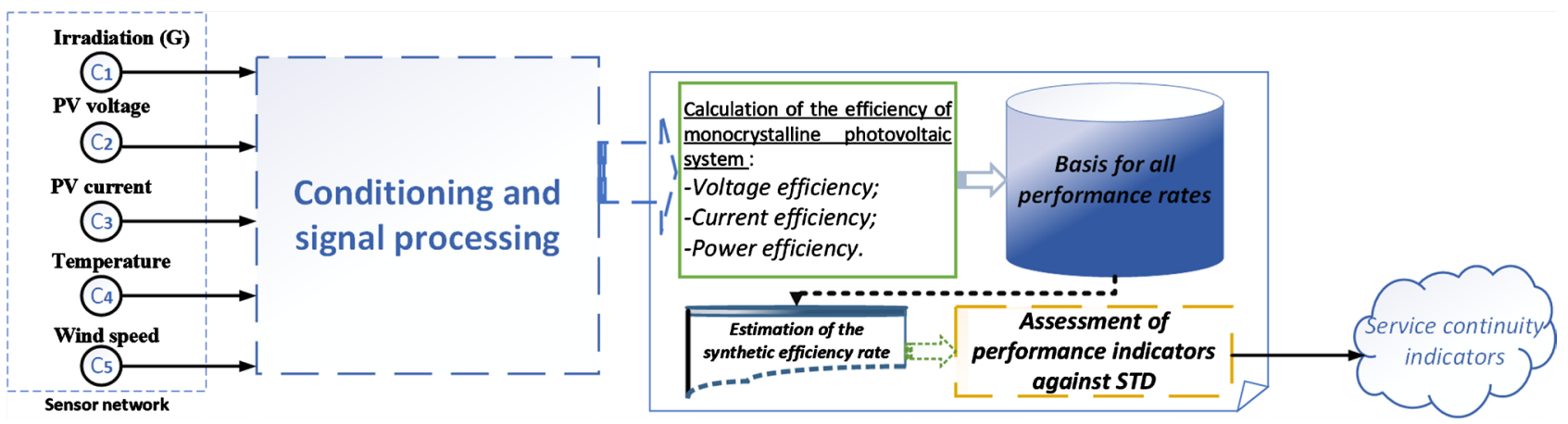

Figure 1. Performance evaluation flowchart.

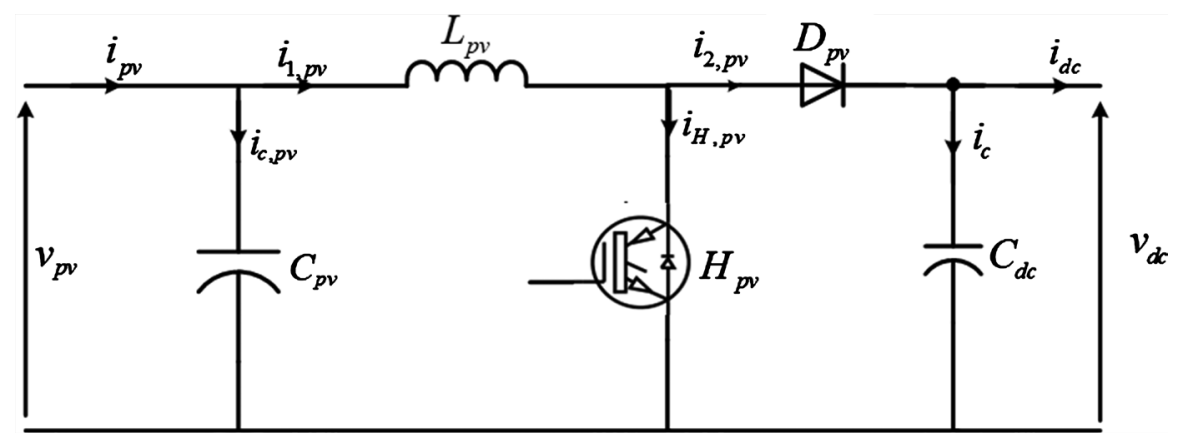

Figure 2. Experimental boost chopper.

$$
\frac{\mathrm{d}}{\mathrm{d} t}\left[\begin{array}{c}
i_{1, p v} \\
v_{p v} \\
v_{d c}
\end{array}\right]=\left(\begin{array}{ccc}
0 & \frac{1}{L} & \frac{1-\alpha}{L} \\
-\frac{1}{C_{1}} & 0 & 0 \\
\frac{1-\alpha}{C_{2}} & 0 & 0
\end{array}\right)\left[\begin{array}{c}
i_{1, p v} \\
v_{p v} \\
v_{d c}
\end{array}\right]+\left(\begin{array}{c}
0 \\
\frac{1}{C_{1}} \\
-\frac{1}{C_{2}}
\end{array}\right)\left[\begin{array}{lll}
1 & i_{p v} & i_{d c}
\end{array}\right]
$$

where $\alpha$ is the cyclic ratio, $i_{p v}, v_{p v}$ respectively the current and the voltage of the photovoltaic solar panel, $i_{d c}, v_{d c}$ respectively the current and voltage of charge, $C_{1}, C_{2}$ filter capacitors, $L$ the inductance et $i_{1, p v}$ the current through the inductance.

$$
\left\{\begin{array}{l}
i_{1, p v}(k+1)=\left(1+\frac{T}{L}\right) i_{1, p v}(k)-\frac{T}{L}(1-\alpha) v_{p v}(k) \\
v_{p v}(k+1)=\frac{T}{C_{1}}\left(i_{p v}(k)-i_{1, p v}(k)\right)+v_{p v}(k) \\
v_{d c}(k+1)=\frac{T}{C_{2}}\left((1-\alpha) i_{1, p v}(k)-i_{d c}(k)\right)+v_{d c}(k) \\
\alpha=\frac{v_{d c}(k)}{v_{p v}(k)}
\end{array}\right.
$$

With $T$ the sampling time. Figure 3 describes the principle of performance evaluation according to the levels prescribed by NFE 60-182 standard. It will be used as a reference in the analysis of the results obtained. Where $T_{q j}$ represents the voltage efficiency, current efficiency or power efficiency $j=\{u, i, p\}$. 


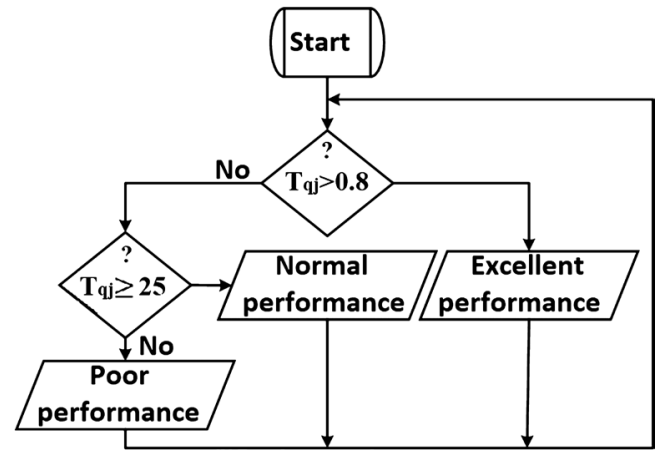

Figure 3. Performance analysis flowchart.

(a)

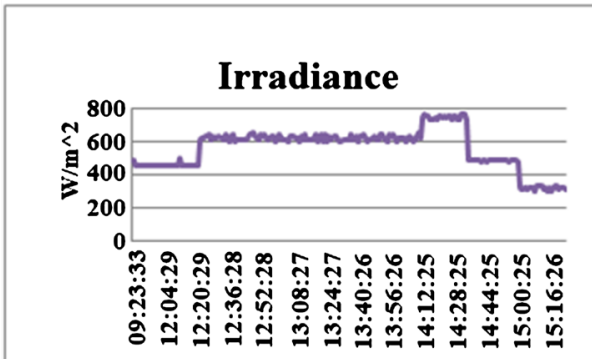

(c)

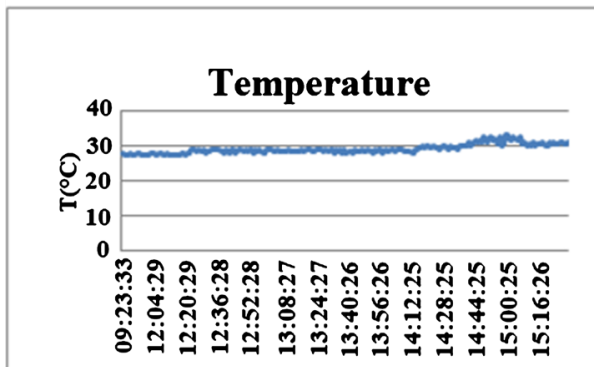

(b)

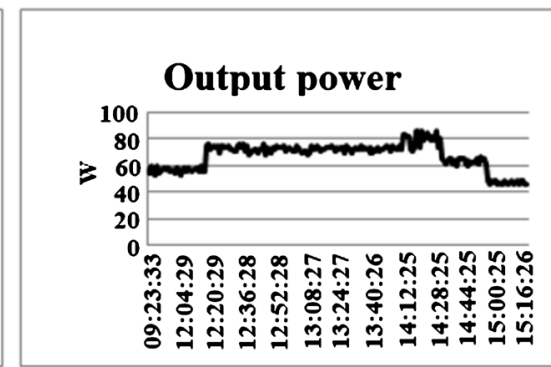

(d)

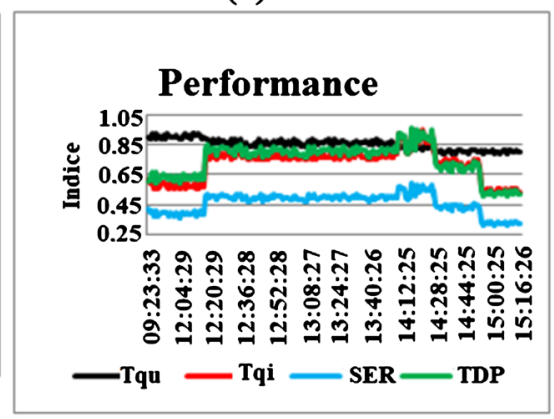

Figure 4. Performance test. (a) Irradiance evaluation, (b) panel power output, (c) daytime temperature, (d) panel performance.

\section{Results and Discussion}

In order to evaluate the performance of the LW-MS90 photovoltaic panel in the coastal region of Cameroon (Douala), we subjected the panel to daily climatological tests. The test conditions depend on the irradiation profiles presented in Figure 4(a), Figure 5(b) and temperatures in Figure 4(c) and Figure 5(d). These figures show an almost constant evolution of temperature during the period of operation of the system. The solar irradiation reaches peaks ranging from about to. The performance tests over the two days of the trial shows the city of Douala as a suitable area for the use of the solar panels. The available power during the usage time depending on the solar irradiation ranges from $40 \%$ to about $80 \%$ without compensation batteries (Figure $4(\mathrm{~b})$ and Figure $5(\mathrm{f})$ ). The performance indicators in Figure 4(d) and Figure 5(h) show that the energy production rate of the LW-MS90 panel in the city of Douala is excellent according 
(a)

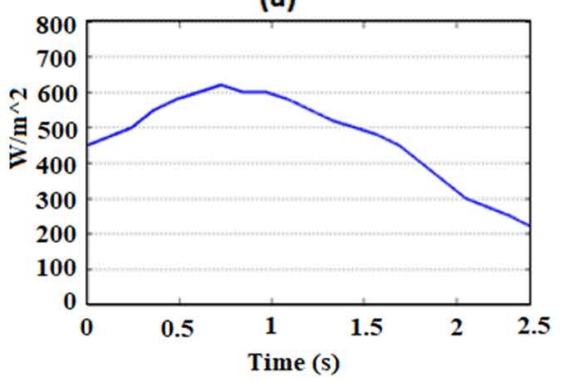

(c)

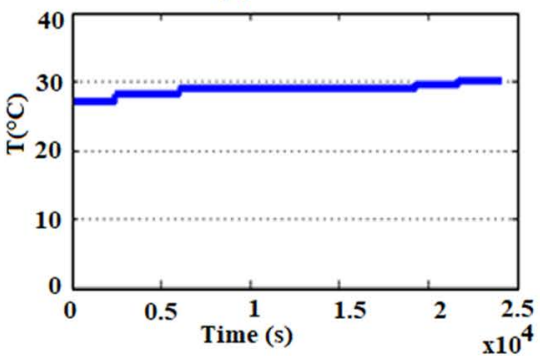

(e)

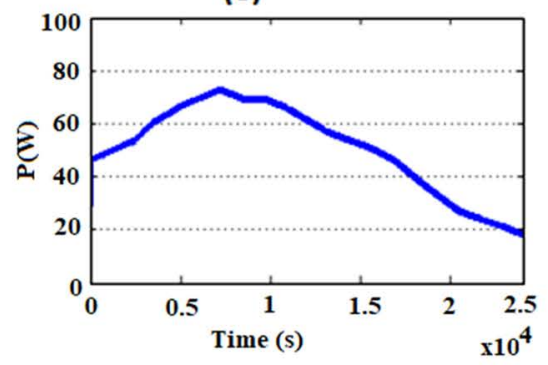

(g)

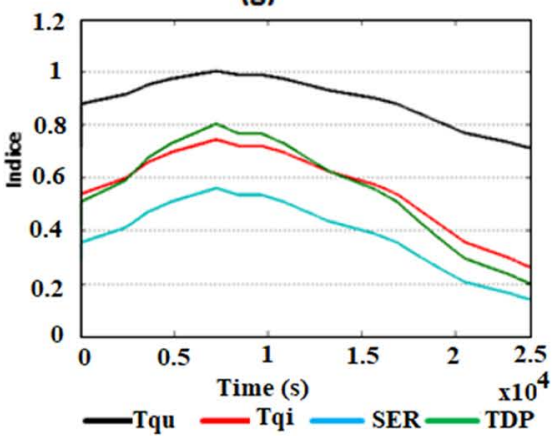

(b)

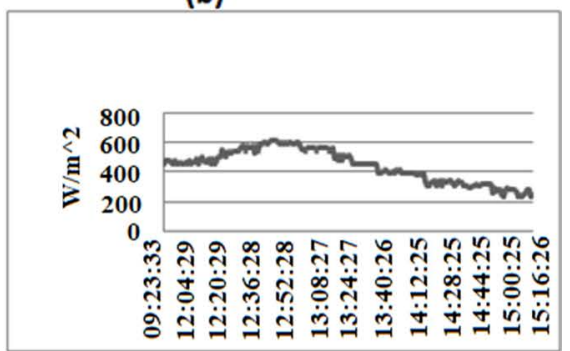

(d)

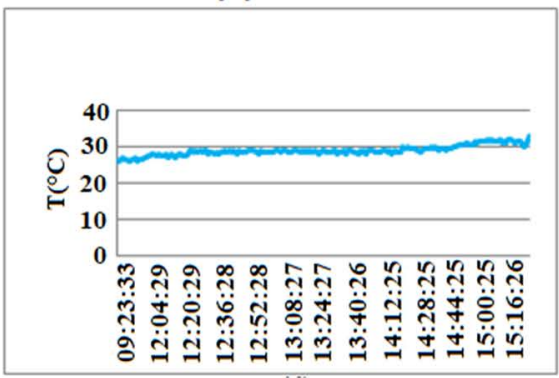

(f)

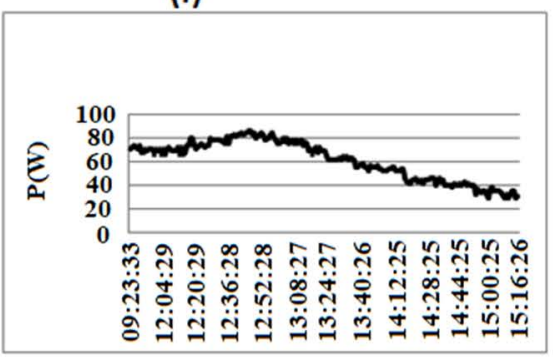

(h)

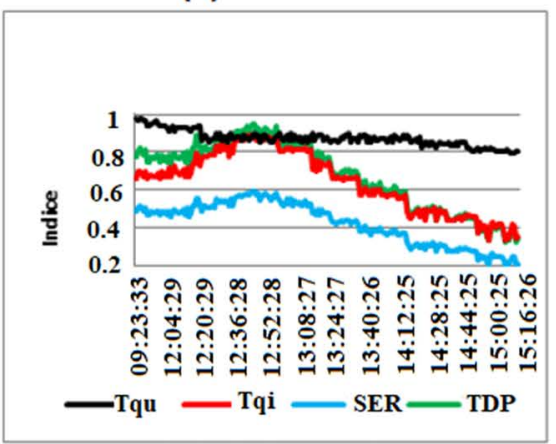

Figure 5. Comparative performance test. (a) simulated solar irradiance implemented in MATLAB/Simulink, (b) measured solar irradiance, (c) simulated temperature, (d) measured temperature, (e) predicted power, (f) measured power, (g) predicted performance, (h) performance obtained with measurements.

to the NFE 60-182 standard. In order to analyse the performance under test conditions, an acquisition and processing system composed of two blocks is implemented: An algorithm developed on MATLAB that allows to retrieve the parameters of the ambient environment to predict the irradiance and an electronic module composed of temperature sensors, a wind speed sensor also called anemometer, and a current sensor to calculate the performance level of the PV 
panel. The comparative results in Figure 5 show that PV installations are an important source of energy production that should be considered for any developing country. The system performance indices give a wide range of normal operation that can show excellent performance under favourable climate conditions. However, it is recognised that the system cannot operate for long periods of time.

\section{Conclusions}

In this paper, we have studied the performance of PV panels in the littoral zone. The aim is to help engineers with the problems of characterising the performance in this zone. This problem causes many effects after installation of photovoltaic systems in the Cameroonian coastal area. The study was conducted to evaluate the performance indices of a specified panel type. The analysis system is based on the synthetic rate of return (SRR) used to establish the performance level. This approach allowed us to use supervised learning (human capacity) in an Expert System to predict the irradiance in the city of Douala through temperature and wind speed to illustrate the performance of the PV panel. The simulation and experimental results presented allowed us to validate the approach. The comparative performance of the indices of current, power, voltage and SER validates the experimental test. For a better prediction of the performances, we will first consider the annual meteorological parameters of the city of Douala and then all the data of the national triangle so that the system can be exploitable in all the cities of the country.

As a perspective of this work, we intend to study and give a descriptive model of the degradation and aging of the photovoltaic panel in the city of Douala.

\section{Conflicts of Interest}

The authors declare no conflicts of interest regarding the publication of this paper.

\section{References}

[1] Adelstein, J. and Sekulic, B. (2005) Performance and Reliability of a $1 \mathrm{~kW}$ Amorphous Silicon Photovoltaic Roofing System. The 31 st IEEE Photovoltaics Specialists Conference and Exhibition, Lake Buena Vista, 3-7 January 2005, 1.

[2] Andrei, H., Dogaru-Ulieru, V., Chicco, G., Cepisca, C. and Spertino, F. (2007) Photovoltaic Applications. Journal of Materials Processing Technology, 181, 267-273. https://doi.org/10.1016/j.jmatprotec.2006.03.043

[3] Jordan, D.C., Silverman, T.J., Wohlgemuth, J.H., Kurtz, S.R. and VanSant, K.T. (2017) Photovoltaic Failure and Degradation Modes. Progress in Photovoltaics, Research and Applications, 25, 318-326. https://doi.org/10.1002/pip.2866

[4] Cameroon Voice (2014) Le Cameroun veut produire 3000 MW d'élctricité pour atteindre un taux de croissance de $9,5 \%$. Cameroun.

https://www.google.com/amp/s/www.investiraucameroun.com/index.php/energie/1 808-5560-le-cameroun-a-besoin-de-3000-mw-d-electricite-pour-atteindre-un-tauxde-croissance-de-9-5/amp 
[5] Bagdonavicius, V. and Nikulin, M. (1995) On Accelerated Testing of Systems. European Journal of Diagnosis and Safety in Automation, 5, 307-316.

[6] Berman, D. and Faiman, D. (1997) EVA Browning and the Time-Dependance of I-V Curve Parameters on PV Modules with and without Mirror-Enhancement in a Desert Environment. Solar Energy Materials and Solar Cells, 45, 401-412. https://doi.org/10.1016/S0927-0248(96)00087-6

[7] ARSEL Cameroun (2014) Mission d'étude sur les énergies renouvelables. Ministère de l'eau and de l'énergie, Cameroun.

[8] IRENA (2015) L'Afrique and les énergies renouvelables: La voie vers la croissance durable. http://www.irena.org/Publications

[9] Carbabaye, A. and Laulheret, R. (2005) Evaluation de la sûreté de fonctionnement des systèmes dynamiques par modélisation récursive. Proc. QUALITA.

[10] Maksimovic, D., Thottuvelil, A.M. and Verghese, G.C. (2001) Modelling and Simulation of Power Electronic Converters. Proceedings of the IEEE, 89, 898-912. https://doi.org/10.1109/5.931486

[11] Ababacar, N. (2013) Étude de la dégradation and de la fiabilité des modules photovoltaïques-impact delapoussière sur les caractéristiques électriques deperformance. Thèse en Sciencesdel'ingénieur, EcoleSupérieure Polytechnique (ESP)-UCAD.

[12] Tolok Nelem, A., Ele, P., Alioune Ndiaye, P., Ndjakomo Essiane, S. and Pesdjock, M.J.P. (2021) Dynamic Optimization of Switching States of a Hybrid Power Network. International Journal of Control, Automation and Systems, 19, 1-11. https://doi.org/10.1007/s12555-020-0088-3

[13] Ndjakomo Essiane, S., Ngo Bissé, J.T. and Pesdjock, M.J.P. (2020) Simple Adaptive Synergetic Control Scheme Based on the MIT Rule of the DC Motor. European Journal of Applied Physics, 2, 1. https://doi.org/10.24018/ejphysics.2020.2.6.30

[14] Nettari, Y. (2014) Commandes robustes and intelligentes des convertisseurs dc-dc. Magister, Université Ferhat Abbas/Setifi, ufasi, Faculté de technologie Algérie.

[15] Laronde, R., Abderafi, C. and Bigaud, D. (2011) Fiabilité d'un module photovoltaïque par les essais accélérés. Laboratoire LASQUO ISTIA, Universitéd'Angers, Angers. 